\title{
The Link between Cytokine Gene Polymorphisms and Recurrent Miscarrage
}

\author{
AL Azzawie HF* \\ Department Department of Biotechnology, Baghdad University, Iraq \\ *Corresponding author: AL Azzawie HF, Department Department of Biotechnology, Baghdad University, Iraq \\ Submission: 侮 August 28, 2017; Published: 侮 November 13, 2017
}

\begin{abstract}
Mini Review
Recurrent miscarriage (RM), defined as three or more consecutive pregnancy losses before 20 weeks of gestation, affects approximately $1-5 \%$ of pregnant women [1]. The etiology of RM is still unclear. Among the large number of miscarriage-related factors, are uterine structural defaults, defective ploidy control of the embryo, defective immunological dialog between the embryo (or the fetus) and the uterus sometimes in relation with immunological disorders (such as autoimmune diseases), thrombophilia, and free radical metabolism imbalance [2]. Numerous studies attempted to correlate variants of genes supposed to be intervening in the different facets of the early maternal-fetal or maternal embryonic dialog, and eventually modify the outcome of fertilization, leading to success or failure of post implantation' development.
\end{abstract}

The objective of the present review is to portray the cytokine gene polymorphisms studied for their putative association with recurrent pregnancy loss. Most of these genes have been studied as candidate genes for which strong biological arguments were put forward as to their putative involvement in recurrent pregnancy loss [3]. Pregnancy depends on the induction of maternal tolerance to fetal tissues; decidual cells will inhibit maternal immunity during pregnancy. Natural killer cells migrating into the uterus during implantation and coordinate the secretion of cytokines that help or limit trophoblast invasion [4]. An increase in of $\mathrm{Th}_{2}$ cells and a decrease in Th1 cells type will protect the allogenic fetus from infiltrating cytotoxic T cells.

Interleukins are a group of immune modulatory proteins leading a variety of immune reactions in human body. These cytokines also include many molecules that play a part in human conception [2]. IL-1 is produced by cytotrophoblasts at the fetal-maternal interface during early pregnancy and is involved in trophoblast invasion and tissue repair [5]. IL-6, secreted by decidual cell populations, is a potent pro-angiogenic cytokine that stimulates the proliferation of endothelial cells in vitro and regulates the behavior of the female reproductive tract and gestational tissues [5,6]. IL-10, produced by cytotrophoblasts and decidual $\mathrm{T}$ cells, protect the fetal-placental interface by reducing the cytokine secretions of $\mathrm{Th}_{1}$ cells and macrophages [7].
IL-17-positive $\mathrm{T}$ cells accumulate in both the decidua and the peripheral blood in patients with RM [8]. IL-18 induces INF- $\alpha$, leading to the activation of NK cells, which are involved in uterine vascularization and implantation [9]. IL-21 was also identified as a susceptibility gene for RM [10]. IL-6, IL-10 and IL-18 plasma concentrations are higher in women with successful pregnancies than in women with RM [11]. Variants of genes alter the corresponding protein expression levels. Therefore, it was necessary to assess the global frequencies of the variant alleles of interleukins that might cause RM. Single-nucleotide polymorphisms (SNPs) are variations at a single nucleotide position in DNA sequence among individuals. If more than $1 \%$ of the population carries the different nucleotide at a specific position in the DNA sequence, this variation is defined as a SNP. They can occur in non-coding regions, such as the promoters, and coding regions, such as the gene body at a total frequency of approximately every 200-1000 bases. SNPs in promoters are suspected to affect transcription factor binding [12], which may in turn influence interleukin production and thus be associated with RM. While SNPs primarily originate as genetic adaption, genetic recombination and mutations.

The biggest difference between SNPs and mutations is that SNPs are inherited. Most SNPs have no effect on development or health. But some of these genetic differences have proven to be very important to human health. They could alter individual response to specific drugs, susceptibility to environmental factors and increase the risk of developing a particular disease. If those inherited SNPs are high-risk candidates, they deserve our attention, and their investigation will lead to further mechanistic research to develop new treatment programs.

The relationship between interleukin signaling and the immune system are numerous. For instance, IL-12 and IL-18 are involved in uterine vascular development through the regulation of uterine NK cells $[13,14]$. Promoter gene polymorphisms were analyzed for these factors in 125 RM cases and 136 controls and did not demonstrate any significant association [15]. However, another study of 282 patients and 283 controls from Saudi Arabia on IL-18 promoter haplotypes reconstructed from genotyping four SNPs 
showed several haplotypes associated with reduced IL-18 levels and increase RM risk [16].

A more recent study extended to a Tunisian population the analysis of the same haplotypes of four SNPs of IL-18 were associated with an increased risk of RM (OR: 20.73 and 5.23, respectively), and C-G-A-G conferred a protection (OR: 0.29). Overall, these allelic combinations are found in $54 \%$ of the controls and $35 \%$ of the patients, which give them an important potential predictive value [17]. On the other hand two studies in Iraqi population the first showed association between Cytokine gene promoter polymorphisms of Interleukin IL-2 (-330 A/T) and TNF- $\alpha$ (-308 G/A) and IL-27 with recurrent pregnancy loss in Iraqi women while IL-10(-1082 A/G) gene promoter was not a risk factor for RSA in Iraqi women [18-20]. In addition a second study done by Alazzawie and his workers who found association between RM and three HLA-G alleles(HLA-G*0103,HLA-G*0104 and HLA-G*0105N) and 14-bp insertion/deletion polymorphism in exon 8 of the 3 untranslated region (3 UTR)frequency and genotypes in idiopathic RM Iraqi women [21-23].

Overall, meta analyses may help to clarify the issues of the impact of cytokine polymorphism and RM, such as that of Bombell and McGuire 24 which evaluated studies on TNFa, IFNg, IL-1 $\beta$, Il-6, and IL-10 and concluded that IL-1 $\beta$ (-31T, at risk, OR: 2.12, CI: 1.04-4.33, from two studies) and IL-6 (-634G, OR: 0.22, 95\% CI: $0.09-0.57$, but from one study only) had significant effects. In 2009, another meta analyses concluded on the effect of the IL-10 genotype [25]. A report combining experiments and meta analyses of IL-1 $\beta$ and IL1RN VNTR on a sample of Indian women did not find the association of variants of these genes with RM [26]. A similar meta analyses concluded the absence of significant effect of IL- 6 and IFN $\gamma$, but comforted the idea of an association of IL-10 $-1082 \mathrm{~A} / \mathrm{G}$ with the risk of RM.

As shown before, the genetic study of pregnancy loss focused overall on a limited number of genes, which have been analyzed in numerous human populations. Following these observations, two hypotheses can be proposed: either (1) The major genes have already been found and duly studied and they explain much of the genetic bases of RM or, on the contrary, (2) this phenotype is so complex that many genes with small effects can cause the disease, and the systematic study of some of them results from a very partial understanding of the causes underlying RM.

One such example is MTHFR enzyme, which is ubiquitously expressed, is responsible for the synthesis of 5-methyltetrahydrofolate.This molecule is the main methyl donor allowing conversion of homocysteine to methionine. Another possible approach to discover new genes is to use information gleaned from model species, following genome scans. This was recently performed in an interspecific recombinant congenic collection of mice followed during gestation by ultra sonography [27] which recently allowed proposing human alkaline phosphatase polymorphisms to be associated with increased or decreased risk of pregnancy loss [28].
Different genetic cascade defects can result in pregnancy loss. Very few studies on humans revealed functional insights on the events ending in pregnancy termination. Some pieces of this puzzle may definitely be missing today, but it would be of great importance to move to more mechanistic models to better understand the genetic bases of abortion.

\section{References}

1. Griebel CP, Halvorsen J, Golemon TB, Day AA (2005) Management of spontaneous abortion. Am Fam Physician 72(7): 1243-1250.

2. Baek KH, Lee EJ, Kim YS (2007) Recurrent pregnancy loss: the key potential mechanisms. Trends Mol Med 13(7): 310-317.

3. Raghupathy R, Kalinka J (2008) Cytokine imbalance in pregnancy complications and its modulation. Front Biosci 13: 985-994.

4. Justine SF, Cilia A, Angela MA, Bhai MR, Wittaya C, et al. (2011) Cytokines Regulating Trophoblast Invasion. Advances in Neuroimmune Biology 2(1,2): 61-97.

5. Denney J, Nelson EL, Wadhwa PD, Waters TP, Mathew L, et al. (2011) Longitudinal modulation of immune system cytokine profile during pregnancy. Cytokine 53(2): 170-177.

6. Bohiltea CL, Radoi VE (2014) Interleukin-6 and interleukin-10 gene polymorphisms and recur $\neg$ rent pregnancy loss in Romanian population. Iran J Reprod Med 12(9): 617-622.

7. Bansal AS (2010) Joining the immunological dots in recurrent miscarriage. Am J Reprod Immunol 64(5): 307-315.

8. Bahadori M, Zarei S, Zarnani AH, Zarei O, Idali F, et al. (2014) IL-6, IL10 and IL-17 Gene Polymorphisms in Iranian Women with Recurrent Miscarriage. Iran J Immunol 11(2): 97-104.

9. Deniz G, Erten G, Kucuksezer UC, Kocacik D, Karagiannidis C, et al. (2008) Regulatory NK cells suppress antigen-specific T cell responses. J Immunol 180(2): 850-857.

10. Messaoudi S, Al-Khateeb GM, Dendana M, Sater MS, Jazia KB, et al. (2011) Genetic variations in the interleukin-21 gene and the risk of recurrent idiopathic spontaneous miscarriage. Eur Cytokine Netw 22(2): 123-126.

11. Ahmed M, Nidhal A (2011) Evaluation of IL-2, IL-18, and IL-10 expression in trophoplastic tissue of women with spontaneous miscarriage. Hum Reprod Update 17: 558-574.

12. Zammiti W, Mtiraoui N, Cochery NE, Mahjoub T, Almawi WY, et al.(2006) Association of $-592 \mathrm{C} / \mathrm{A},-819 \mathrm{C} / \mathrm{T}$ and $-1082 \mathrm{~A} / \mathrm{G}$ interleukin-10 promoter polymorphisms with idiopathic recurrent spontaneous abortion. Mol Hum Reprod 12: 771-776.

13. Al-Khateeb GM, Sater MS, Finan RR, Mustafa FE, Al-Busaidi AS, et al. (2011) Analysis of interleukin-18 promoter polymorphisms and changes in interleukin-18 serum levels underscores the involvement of interleukin-18 in recurrent spontaneous miscarriage. Fertil Steril 96(4): 921-926.

14. Atsushi F, Ayano F, Kohei F, Hitomi C, Megumi Y, et al. (2015) NK cell abnormality and its treatment in women with reproductive failures such as recurrent pregnancy loss, implantation failures, and pelvic endometriosis. Reproductive Medicine and Biology 14(4): 151-157.

15. Ru XL, Ying W, Li HW (2015) Relationship between cytokine gene polymorphisms and recurrent spontaneous abortion. Int J Clin Exp Med 8(6): 9786-9792.

16. Alkhuriji AF, Alhimaidi AR, Babay ZA, Wary AS (2013) The relationship between cytokine gene polymorphism and unexplained recurrent spontaneous abortion in Saudi females. Saudi Med J 34(5): 484-489.

17. Messaoudi S, Dandana M, Magdoud K, Meddeb S, Ben Slama N, et al. (2012) Interleukin-18 promoter polymorphisms and risk of idiopathic 
recurrent pregnancy loss in a Tunisian population. J Reprod Immunol 93(2): 109-113.

18. Azzawie AH, Israa AA (2017) Association between Cytokine gene promoter polymorphisms of Interleukin IL-2 (-330 A/T) and TNF- $\alpha$ $(-308 \mathrm{G} / \mathrm{A})$ with recurrent pregnancy loss in Iraqi women . Int J Curr Microbiol App Sci.

19. Azzawie A Israa AA (2015) The Relationship between Single Nucleotide Polymorphism of Interleukin -10 Gene Promoter (-1082 A/G) with Recurrent Spontaneous Abortion in Iraqi Women. BBB (3-4): 537-545.

20. Esraa HH, Hamad LH, Hasan FA, Samera HH (2017) Hamad4,Single Nucleotide Polymorphism of Interleukin-27 Gene: A Risk Factor of Recurrent Pregnancy Loss in Iraqi Women. Electronic Journal of Biology 13(2): 119-124.

21. Reema MA, Hasan FA, Kareem A (2016) The impact of 14bp insertion/ deletion polymorphisms in exon 8 of HLA-G and its expression by RTPCR and Immuno histochemical methods in unexplanied miscarriage Iraqi women. ejpmr 3(12): 138-144.

22. Reema MA, Hasan FA, Kareem A (2016) HLA-G 14 bp Insertion / Delection polynmorphisms in recurrent pregnancy loss among a sample of Iraqi women. Int J Adv Res 4(11): 1642-1647.
23. Reema MA, Hasan FA, Kareem A (2016) Genetic polymorphisms of HLA-G antigen in iraqi women with unexplained recurrent miscarriage. Int J Adv Res 4(11): 1654-1663.

24. Bombell S, McGuire W (2008) Cytokine polymorphisms in women with recurrent pregnancy loss: Meta-analysis. Aust N Z J Obstet Gynaecol 48(2): 147-54.

25. Medica I, Ostojic S, Pereza N, Kastrin A, Peterlin B (2009) Association between genetic polymorphisms in cytokine genes and recurrent miscarriage-a meta-analysis. Reprod Biomed Online 19(3): 406-414.

26. Agrawal S, Parveen F, Faridi RM, Prakash S (2012) Interleukin-1 gene cluster variants and recurrent pregnancy loss among North Indian women: Retrospective study and meta-analysis. Reprod Biomed Online 24(3): 342-351

27. Laissue P, Burgio G, lHote D, Renault G, Marchiol FC, et al. ( 2009) Identification of Quantitative Trait Loci responsible for embryonic lethality in mice assessed by ultrasonography. Int J Dev Biol 53(4): 623-629.

28. Vatin M, Bouvier S, Bellazi L, Montagutelli X, Laissue P, et al. (2014) Polymorphisms of human placental alkaline phosphatase are associated with in vitro fertilization success and recurrent pregnancy loss. Am J Pathol 184(2): 362-368. 